\title{
Cross-cultural Training and Second Language Learning
}

\author{
Zhonghao Zhou ${ }^{1}$ \\ ${ }^{1}$ Guangdong Civil Affairs School, Guangzhou, China \\ Correspondence: Zhonghao Zhou, Guangdong Civil Affairs School, Guangzhou, China.
}

Received: August 29, 2017

Accepted: September 9, $2017 \quad$ Online Published: September 19, 2017

doi:10.20849/aes.v2i3.176

URL: https://doi.org/10.20849/aes.v2i3.176

\begin{abstract}
Culture and language are inseparable, and cultures as groups adopt particular practices and norms of behavior. Culture teaching is a long and complex process concerning something more than language use itself. The two popular theories influencing practice today are the Constructivist and the Creative Constructionist approaches, and the technique for conveying cultural awareness is cultural assimilator, which has been designed for specific cultures around the world. Cross-cultural training can be used to promote cultural awareness, that is, sensitize people to the influence of culture on people's values and behaviors and help them recognize and accept the existence of cultural differences.
\end{abstract}

Keywords: culture, second language learning, behavior, skill

\section{Introduction}

Culture has many different dimensions, including ideas, customs, skills, arts and tools that characterize a group of people in a given period of time. It is also the beliefs, values, and material objects that create our way of life. Culture establishes a context of cognitive and affective behavior for each person. It influences individual estimation and attitudes, and can also have an effect on practical aspects of life such as hobbies. People begin with habitual actions and go on to create common stereotypes. The stereotypes assign group characteristics to individual purely on the basis of their cultural membership. The cultural stereotypes affect how people think, speak, act, and interact with one another. Culture and communication are inseparable because culture not only dictates who talks to whom, about what, and how the communication proceeds, but also helps to determine how people encode messages, the meanings they have for messages, and the conditions and circumstances under which various messages may or may not be sent, noticed, or interpreted. In a word, culture is the foundation of communication.

\section{Language and Culture}

\subsection{Language}

Language is what people use to express, create and interpret meanings and to establish and maintain social and interpersonal relationships. This understanding of language views language not simply as a kind of knowledge to be learnt, but as a social practice in which to participate. It is not enough for language learners just to know grammar and vocabulary. They also need to know how that language is used to create and represent meanings and how to communicate with others and to engage with the communication of others. This requires the development of awareness of the nature of language and its impact on the world.

The role of language in learning cannot be over-emphasized. Language is the prime resource teachers have and use for mediating learning. When learning languages, teachers and students are working with language simultaneously as an object of study and as a medium for learning. In teaching languages, the target language is not simply a new code, new labels for the same concepts. When it is effectively taught, the new language and culture being learned offer the opportunity for learning new concepts and new ways of understanding the world (Dumitrašković, 2014). Second language learning is comprised of several components, including grammatical competence, communicative competence, language proficiency, as well as a change in attitudes towards one's own or another culture. For scholars and laymen alike, cultural competence, i.e., the knowledge of the conventions, customs, beliefs, and systems of meaning of another country, is indisputably an integral part of second language learning, and many teachers have seen it as their goal to incorporate the teaching of culture into second language curriculum (Thanasoulas, 2001). It could be maintained that the notion of communicative competence, which in the past decade or so, has blazed a trail in second language teaching, emphasizing the role 
of context and the circumstances under which language can be used accurately and appropriately.

\subsection{Group and Culture}

Human being lives as a member of a group. One's cultural orientation begins at birth. As one grows and learns his first language, he is acculturated into a particular way of life. Therefore when a second language learner begins a new language, the learner is no more a 'blank slate' culturally than they are linguistically. Pedagogical approaches and techniques that help learners to reflect objectively on their own culture are especially important because language teachers and learners need to be aware of their point of departure in culture learning. The importance of the learner gaining an objective viewpoint is also evident when roles for the learner as researcher, ethnographer or anthropologist in culture learning are recommended.

A group perspective on culture draws attention to the idea of membership and community and leads to questions such as how people identify with groups, how others identify people with groups and how different groups relate and interact with one another. Generally, we know immediately whether we belong, whether we are insiders or outsiders, welcomed, resisted, in relation to a particular group. Groups and cultures are distinguished from one another by a wide variety of means: geographical location, political persuasion, religion, clothing, food and so on Importantly, groups are also circumscribed and defined by the language they share. Cultures operate on the basis of membership, realized through formal or informal means. As a general rule, individuals are not entirely free to move in and out of the group at will, though the mechanisms of regulation vary. Of course, language plays a key role in negotiating membership. Cultures as groups adopt particular practices and norms of behavior, sometimes involving explicit or implicit rules and codes of conduct. One becomes a member of the culture not only by notionally agreeing to its practices, or simply by participating in them, but by being accepted by the membership.

Membership is not solely in the hands of the potential participant, it is also subject to the varied and subtle ways in which the group chooses to accept or reject members (Levy, 2007). The influence of cultural differences contributing to a communication problem can be recognized in many of the example data extracts of native speaker vs. non-native speaker conversations. The reason lies in the centrality of cultural norms and conventions for deriving meaning from context.

\subsection{Culture and Language Are Inseparable}

It is argued that language has a dual property, both as a means of communication and a carrier of culture. Language without culture is unthinkable, so is human culture without language. A particular language is a mirror of a particular culture. The relation between language and culture as follows, a language is a part of a culture and a culture is a part of a language. They are intricately interwoven so that one cannot separate the two without losing the significance of either language or culture. In a word, culture and language are inseparable. When it comes to the realm of teaching and learning, the interdependence of language learning and cultural learning is so evident that one can conclude that language learning is culture learning and consequently, language teaching is cultural teaching. Second language teachers should be aware of the place of cultural studies in second language classroom and attempt to enhance students' cultural awareness and improve their communication competence.

Globalization is one of the reasons to teach culture as a fifth language skill, in addition to listening, speaking, reading and writing. What the fifth language skill teaches us is the mindset and technique to adapt our use of the target language to learn about, understand and appreciate the values, ways of doing things and unique qualities of other cultures (Choudhury, 2014). It involves understanding how to use language to accept differences, to be flexible and tolerant of ways of doing things which might be different to yours. It is an attitudinal change that is expressed through the use of language. Teaching culture in second language teaching should include cultural knowledge (knowledge of culture), cultural values (what people think is important), cultural behavior (knowledge of daily routines and behavior), and cultural skills (the development of intercultural sensitivity and awareness).

\subsection{Teaching Culture in SLA}

People growing up in a social group learn ways of viewing things, doing things, expressing things and solving certain problems in certain ways. They also learn to value something and despise or avoid other things. These attitudes, reactions and emotions become part of their ways of life without being conscious of them. Yet these culturally determined features actually have rooted in a deeper and more significant social conventions, relations and assumptions which are composed of the main stream of a culture of a nation. A language is learned and used within such a context, drawing from the culture distinctive meanings and functions which must be assimilated by language learners if they are to control the languages as native speakers control it. Culture teaching is a long and complex process concerning something more than language use itself. Its aim is to increase students' awareness 
and to develop their interest towards the target culture and their own, helping them to make comparisons among cultures. The comparisons are not meant to underestimate any of the cultures being analyzed, but to enrich students' experience and to make them aware that although some culture elements are being globalized, there is still diversity among cultures. This diversity should then be understood, and never underestimated.

Second language teachers should be second culture teachers, with the ability to experience and analyze both the home and target cultures. Teachers of the culture of a linguistic community need to know the culture to be taught and know the culture of the language learners $(\mathrm{Qu}, 2010)$. Whether the native speaker or the second language teacher, those who wish to present another culture in a way to foster intercultural understanding and appreciation will need to acquire special knowledge of how cultures are organized: their value system, their institutions, their interpersonal relationships. If possible, teachers should live for some time in both the cultures to be taught. If this is not possible, they must compensate for the lack by disciplined reading. They must read what the people living in the culture read, listen to the radio and watch the television where accessible, and watch films made of local consumption. If possible, they should contact with native speakers, discussing all kinds of subjects with them and in this way they could educate themselves in cultural interpretation.

\subsection{Intercultural Interaction}

The nowadays world is becoming more and more interdependent and interconnected. Interaction between peoples of different cultures is increasing, as international cooperation, economic and technical assistance, and political and economic integration grow in magnitude. The future depends on man who is capable of exceeding the limits of individual cultures, since technical solutions to environmental problems will never be applied rationally until man has exceeded the limitations imposed by his culture. It is well established that each individual has his or her own subjective reality, which can result in misunderstanding in relationships with others, even in ordinary intercultural circumstances.

Therefore, it would seem reasonable to expect that the potential for problems in intercultural interaction is even greater, since there are often major differences in values, attitudes, beliefs, and expectations. While schools are being urged to educate young people in cross-cultural understanding, the real question is how to accomplish this. Although there are various models of cross-cultural training available in the literature, not all of them are equally applicable or desirable in school settings. The majority of students at school do not have much opportunity to gain understanding of different cultures from other countries (Aoki, 1992). They do not expect to encounter such cultures on a very personal basis, and consequently possess low motivation for learning about other cultures. Yet, these students are undoubtedly the ones who need it most.

This study aims to explore the nature and approaches of cross-cultural training in second language learning. It will review the major concepts, opinions and approaches, make comments on them, and bring new insights on the importance and approaches on cultural learning in second language acquisition. It will be significant in for the students to obtain cross-cultural consciousness and improve their communicative ability.

\section{Language Learning and Culture Learning}

\subsection{Learner Centered Education}

For learner centered education, the first step should be the collection of information about learners, and the most valuable learner data can only be obtained in an informal way after relationships have been established between teachers and learners. Recent initiatives suggest some forward-thinking ideas in education at all levels, and several examples of emergent thinking are worthy of mention. In the UK schools sector, The Royal Society for the Encouragement of Arts, Manufactures and Commerce developed the Opening Minds framework which aims to help schools provide young people with the real world skills or competencies they need to thrive in the real world, in an alternative to a strictly subject-based curriculum. Used in over 200 schools, Opening Minds was developed in response to a belief that the way young people were being educated was becoming increasingly detached from their needs.

In the US, a framework has been put forward, which emphasizes the skills, knowledge and expertise that students must master to succeed in work and life. They cover three areas: Learning and Innovation (creativity, critical thinking, problem solving, communication, collaboration); Information, Media and Technology (information and media); and finally, Life and Career (this includes flexibility and adaptability, initiative and self-direction, social and cross-cultural skills, productivity and accountability, leadership and responsibility). The MILE Guide Self-Assessment Tool shows the envisaged outcomes of skills development, stating that ultimately students will be active collaborators in the teaching and learning process, acting as co-creators of knowledge along with other students, teachers and education leaders, engaging with project work and inquiry-based learning. 
Similar sentiments are expressed in the UK higher education sector, which put forward the idea that universities need to improve the nexus between research and teaching (Kukulska-Hulme, 2010). To help realize this goal, it is argued that all undergraduate students in all higher education institutions should experience learning through research and inquiry. The goal is to move more curricula in the direction of developing students as participants in research and inquiry, so that they are producers, not just consumers of knowledge.

\subsection{The Constructivist Approach and the Creative Constructionist Approach}

Language learning itself is not a unified activity, as the separate functions of speaking, listening, reading and writing have to be addressed, each at many levels, from phonetics to discourse and pragmatics. The two popular theories influencing practice today are the Constructivist and the Creative Constructionist approaches. The Constructivist approach asserts that learning is an active, creative, and socially interactive process in which learners construct new ideas based upon their current and past knowledge. Knowledge develops via the negotiation of meaning through dialogue with the target language and its many socio-cultural expressions. Successful language learning is therefore achieved through exposure to and interaction with language in authentic contexts. Typically a learner in a Constructivist-inspired program would be required to perform tasks and solve problems involving listening, reading, writing and speaking in the target language, ensuring a high level of interaction.

The Creative Construction position on language learning suggests that language acquirers are not usually aware of the fact that they are learning a language, but acquire the second language by understanding the message or by receiving comprehensible input (Pemberton et al, 2005). Comprehensible input can come from a variety of sources at a level on or slightly above the learner's current level of competence. This input contributes directly to acquisition which is largely responsible for developing comprehension and subsequent productive fluency in a second language. According to this theory, the learners are not required to actually speak or write in order to acquire language. Acquisition takes place internally as learners read and hear understandable samples of the language. In other words, after a great deal of listening, speech will emerge spontaneously in a natural order. Motivation to learn also appears to be one of the most important determinants in successful language acquisition. Krashen suggests that language learning environments must be highly motivating and designed in ways that cause learners to forget that they are hearing or reading another language.

\subsection{Intercultural Language Learning}

One of the approaches in language teaching that has intercultural language learning at its heart involves developing with students an understanding of their own culture, and the recognition of the same in others. Through intercultural language learning, students engage with and learn to understand and interpret human communication and interaction in increasingly sophisticated ways. They do so both as participants in communication and as observers who notice, describe, analyze and interpret ideas, experiences and feelings shared when communicating with others. They engage with interpreting their own and the meanings of others, with each one's experience of participation and reflection leading to a greater awareness of themselves in relation to others (Dumitrašković, 2014). The ongoing interactive exchange of meanings, and the reflection on both the meanings exchanged and the process of interaction is an integral part of life in their world. Intercultural language learning is best understood not as something to be added to teaching and learning, but rather something that is integral to the interactions that already takes place in and beyond the classroom.

Since society and culture has been reduced to a variable elusive of any definition, it stands to reason that the term communicative competence should become nothing more than an empty and meretricious word. In reality, what most teachers and students seem to lose sight of is the fact that knowledge of the grammatical system of a language has to be complemented by the understanding of culture-specific meanings. One of the misconceptions that have permeated second language teaching is the conviction that language is merely a code and one language is essentially translatable into another. To a certain extent, this belief has been instrumental in promoting various approaches to second language teaching, which have certainly endowed the study of language with a social hue (Thanasoulas, 2001). Nevertheless, paying lip service to the social dynamics that undergird language without trying to identify and gain insights into the very fabric of society and culture that have come to charge language in many and varied ways can only cause misunderstanding and lead to cross-cultural miscommunication.

\subsection{Cultural Awareness}

The technique for conveying cultural awareness is cultural assimilator, which has been designed for specific cultures around the world. This self-learning tool permits trainees to read about situations they are likely to encounter as foreigners in the host country, to choose from among different options for managing the situation, and then to receive an expert view of the most appropriate behavior to deal with it. The chief benefit claimed for 
cultural awareness training is that cultural knowledge, especially when reinforced by a certain feel for the culture that assimilator training aims to impart, not only helps to avoid offending the sensibilities of host nationals, but also enhances the likelihood of fruitful collaboration. The empirical evidence for the cultural awareness form of training is similar to that for area studies, broadly supportive but recognizing its limits. It is found that assimilator training, which emphasizes daily-life incidents, is more effective in terms of adjustment and interpersonal relations than general area studies information about the host country.

Pursuing the question further, some people discovered some positive support for the independent efficacy of cultural awareness training. Their experiment compared the improvements made by five groups of white males in their attribution skill concerning black American culture and in the quality of their interactions with black people. The groups were: those receiving a black culture assimilator alone, those undergoing a behavioral contact role-play with black people, those receiving the assimilator followed by the behavioral contact, those receiving the contact prior to the assimilator, and a control group receiving no training at all (Kealey and Protheroe, 1996). The subjects were rated on their skills and knowledge acquisition by black judges. It is found that, while intellectual and behavioral training worked best in tandem, the highest-rated group was the one which did the assimilator followed by the role-play. The researchers believe that the latter finding indicates there may well be an independently positive contribution made by intellectual-based training vehicles in promoting cultural awareness, and that such cognitive knowledge is valuable for reducing anxiety about interpersonal contact with members of the host culture and for integrating experiences so as to get the most out of experiential training.

\subsection{Intercultural Awareness Raising}

It is noted that some cultural norms are likely to be different between the first language land and the second language land. Furthermore, the experience of living in the target culture will physically separate students from their normal micro-communities. A student's success in achieving the linguistic objectives depends on contact with the native people of the community in which he or she will be resident. It is therefore important for the student to be able to empathize with those people and to appreciate, adapt to and function within the norms of that community. Teachers are usually able to recognize the students with relatively poor gain in linguistic ability. Furthermore, a student's lack of awareness of second cultural norms and inappropriate strategies for coping with difference may result in affective and behavioral reactions of culture shock, homesickness, stereotyping of their host community and even xenophobia. Consequently, educating culturally must focus on how the student's feelings, attitudes, actions and reactions can influence the process of adaptation to the cultural norms of the host community.

Intercultural awareness shares some similarity with interlanguage in that the person is influenced by both knowledge and experience of his or her host culture and of his or her native culture. The state of intercultural awareness of the people manifests itself in feelings, attitudes and behaviors which display how well they have adapted to life in the target culture. Intercultural Awareness Raising refers to the development of intercultural awareness through educational methods, and it needs to concern itself with knowledge, feelings, attitudes and behaviors. Intercultural learning is by nature a cognitive and affective and behavioral affair.

Modern languages study has traditionally focused on cognition, aiming to develop intercultural awareness through the analysis of factual texts, deemed by departments or tutors to contain information relevant to life in the target culture (Hall and Toll, 1999). The study of these texts, as well as of artistic works of literature and poetry, may open up discussion of a more experiential and affective nature, depending on the teaching methodologies employed by the tutors. However, the cultural links are often given explicitly in lectures and seminars or provided in critiques. In actual intercourse, the safe distance afforded by text-based study of the second culture from the first culture land is no longer available. Factual knowledge delivered through lectures and seminars and provided in handbooks is often insufficient when put to the test by the day to day emotions in the target culture.

\section{Approaches for Cross-cultural Training}

\subsection{The Socio-cultural Approach}

The socio-cultural approach to the study of second language acquisition is based on findings from a wide range of studies found in such fields as anthropology, first language acquisition, educational research, and cognitive psychology. This approach posits that all behavior is fundamentally pragmatic, organized around the regularities that arise from recurring exposure and mutual alignment to the socio-culturally significant communicative practices. Participation in these practices, which themselves are tied to and thus shaped by their institutional, historical, and cultural settings, is mediated by various constellations of socio-historically developed symbolic tools and resources. Both the structure of these resources and the varied ways in which they are used in the 
development and management of the communicative practices give shape to such fundamental competencies as reason, memory, motivation, and knowledge about the world.

Through extended participation in the practices they develop frameworks of expectations for what counts as knowledge, and for what they can do, both as individuals and as group members, in using the resources to display and build upon their understandings of this knowledge simultaneously. These expectations and the tools and resources they use to mutually display and negotiate this knowledge form the foundation of their mental activity. Individual development begins in the social relationships both framing and framed by extended participation in their communicative practices, and proceeds from these to the psychological activity. This movement from the social to the psychological is guided by assisted participation with other, more experienced participants. The participants also become more proficient in understanding the socio-cultural importance of the practices and their values and goals, and the roles they and the others are appropriated into playing. Eventually, the behaviors become the psychological tools that give shape to the individuals' cognitive development. It is important to note that, given the pragmatic nature of competence, participation in different practices, uses of different resources in similar practices, or even different opportunities and experiences with using similar resources help shape different developmental paths that ultimately lead to the development of differently formed and defined competences (Hall, 1997).

\subsection{Didactic Approach and Experiential Approach}

As societies become more pluralistic and global, acquiring an understanding of other cultures becomes increasingly important, and cross-cultural training is one way to provide this understanding. In particular, cross-cultural training can be used to promote cultural awareness, that is, sensitize people to the influence of culture on people's values and behaviors and help them recognize and accept the existence of cultural differences. Conceptually, this awareness should form the basis for improved communication, interactions, and working relationships with people from different cultural backgrounds. Cross-cultural training programs can make positive contributions to people's cross-cultural skill development, adjustment, and performance, and it has a strong and positive impact on cross-cultural skills development, adjustability, and job performance of expatriate managers.

Most people tend to view didactic approaches, such as lectures and films, as low in trainee involvement and targeted at the cognitive level. In contrast, experiential approaches, such as role plays and simulations, are considered to demand high trainee involvement and to emphasize affective goals. Both didactic and experiential approaches can be used to present culture-specific or culture-general concepts. An important issue concerns the relative effectiveness of didactic and experiential approaches. The didactic model with its emphasis on cognitive goals is useful for conveying and transferring factual and analytical knowledge at the cognitive level. It is economical and provides trainees with an intellectual understanding of different aspects of cross-cultural interactions. This approach has often been criticized as not very useful for effecting meaningful changes in attitudes or behaviors. Some people suggest that traditional classroom activities, such as lectures, discussions, student presentations, and research projects, are important but do not allow trainees to reflect upon their cross-cultural experiences to the extent that experiential activities do.

Unlike the didactic approach, the experiential approach is learner-centered and allows trainees to react to cross-cultural situations intellectually, emotionally, and behaviorally. Experiential learning has been used to understand other cultures in areas such as counseling, language, and management. Advocates of this approach contend that the way to learn about another culture is through real-life experiences in a structured situation. Experiential activities enable trainees to share their cognitive and affective reactions to the activity and obtain some valuable insight from conceptualizing their reflections on the experience. Support for the superiority of experiential approaches over other instructional approaches is, however, mainly anecdotal or judgmental. One experiential method that has been used widely for instructional purposes is simulation games (Gannon and Poon, 1997). In a discussion on the efficacy of simulations, some people argue that simulations provide trainees with an opportunity for discovery whereby the trainee gains receptivity to new ideas, insight, and sensitivity, and that attitude change is greatest when the trainee has a high degree of personal involvement.

\subsection{Folktales}

A folktale is a story, myth or legend forming part of an oral tradition, does not have a single, identifiable author or writer and is or was passed down from one generation to the next. A folktale can change over time, be reshaped by modifications and was often changed with each retelling. As a result, there can be various versions of the same folktale. This will be demonstrated through this book when some folktales are provided with different versions across a number of chapters. As a form of common folklore, folktales sugarcoat the hard 
lessons of life so as to give listeners or readers guidance about how they should behave. In this way, folktales help pass values and beliefs, traditions and culture across the generations. Literature-based language teaching has been considered a common approach to promote both oral and literacy skills. It involves the use of literary works of different types and scopes, ranging from prose and poems to folk chants and folktales to engage learners with meaningful, authentic input. Stories, in general, and folktales, in particular, bring a holistic approach to foreign language teaching and learning. Through stories, learners acquire more than just language knowledge and usage and have opportunities to hear and use language in meaningful, engaging ways. Story-based teaching helps students develop an appreciation as well as an enjoyment of literature and supports the development of all of literacy, oral and social skills at the same time. Students learning through folktales can also develop their imagination and to make use of their creativity. They learn about negotiations and life values through the interactions and behavior of characters.

Stories from the oral traditions of many countries throughout the world provide learners with knowledge about social contexts which are familiar and also exciting. These stories portray contexts through which new language can be introduced and offer insights into different cultures, situations and scenarios in which people from their homeland or from a different country live and behave towards one another, settle conflicts and solve problems (Nhung, 2016). The social contexts described in folktales also present learners with knowledge about how people from many countries thought and believed in earlier times, describing local social settings and the social expectations, thinking and reasoning which may be unique to a specific historical time. Such contexts add to the sense of expectation created by the events in stories and not found in other types of texts.

\subsection{Videos}

Some people believe that video watching should be performed in the same way as the students would watch a film at a cinema in the foreign country: that is, with no formal introduction. In this way, the video experience imitates a natural immersion situation, in which the language learner, with no help from a teacher, acquires the target language by interacting with the foreign culture directly. Some researchers claim, however, that teachers must be careful not to abdicate their responsibility to build successful learning experiences for students. They argue that both first language and second language learners' comprehension skills can benefit from an introductory sequence prior to video viewing. For example, a collaborative film project includes extensive notes on how to preview the videos. Though the videos and support materials on German history, politics, and so forth are in English, the authors recognized the difficulties involved in comprehending film segments about a foreign culture and thus included introductory sequences. Comprehension difficulties are amplified when students are dealing with authentic L2 video materials. Teachers should provide students with an introductory stage prior to video viewing. In this way, students do not attack a listening activity unprepared; their comprehension is facilitated by a framework of clues about what is to come in the video. Along these lines, it is pointed out that just as we would not send our students to a foreign country without any knowledge of its language, history, or culture, it is equally irresponsible to send them off uninformed into an L2 text whose author is unknown to them, from a country and culture that is not their own. Nothing is more natural than to give them information that will orient them to the textual world they are about to enter.

The use of relevant introductory materials to facilitate comprehension and retention of L1 and L2 texts is supported by classroom research. Studies on student comprehension of relatively short reading and listening passages indicate that understanding is enhanced by prior presentation of an anchoring framework such as pictures, key words, or scripts, linked to the context of the passage (Herron et al, 1998). It is shown that students significantly profited from a teacher's brief verbal explanation of principles plus organization of materials prior to reading for comprehension. Educators can stimulate a greater depth of processing, and thus improve retention, by elaborating the expressions at the time of encoding. Pictures, gestures, and pantomime are all ways to elaborate information. The visual context of the description and pictures plus video condition appears to have increased the depth of processing of the advance organizer as measured by greater retention of the subsequent video than in the description only condition.

\section{Conclusion}

There has been a resurgence of interest in the study of language in relation to society in the last two decades, which has led to a shift of focus from behaviorism and positivism to constructivism to critical theory. Yet, there are still some deeply ingrained beliefs as to the nature of language learning and teaching which have contrived to undermine the teaching of culture. The teaching of culture is not akin to the transmission of information regarding the people of the target community or country, even though knowledge about the target group is an important ingredient. It would be nothing short of ludicrous to assert that culture is merely a repository of facts 
and experiences to which one can have recourse. Furthermore, learning a second language is not merely to learn how to communicate but also to discover how much leeway the target language allows learners to manipulate grammatical forms, sounds and meanings, and to reflect upon, or even flout, socially accepted norms at work both in their own or the target culture.

\section{References}

Aoki, J. (1992). Effects of the Culture Assimilator on Cross-Cultural Understanding and Attitudes of College Students. JALT Journal, 14(2), 107-125.

Choudhury, R. U. (2014). The role of culture in teaching and learning of English as a foreign language. Express, an International Journal of Multi Disciplinary Research, 1(4), 1-20.

Dumitrašković, T. A. (2014). Culture, Identity and Foreign Language Teaching and Learning. Journal of Foreign Language Teaching and Applied Linguistics, 6(11), 251-258.

Gannon, M. J., \& Poon, J. M. (1997). Effects of alternative instructional approaches on cross-cultural training outcomes. International Journal of Intercultural Relations, 21(4), 429-446.

Hall, J. K. (1997). A consideration of SLA as a theory of practice: A response to Firth and Wagner. The Modern Language Journal, 81(3), 301-306.

Hall, S., \& Toll, S. (1999). Raising Intercultural Awareness in preparation for periods of residence abroad: A review of current practice in UKHE. Retrieved from www.lancaster.ac.uk/users/interculture/docs/ria.rtf

Herron, C., Cole, S. P., York, H., \& Linden, P. (1998). A comparison study of student retention of foreign language video: Declarative versus interrogative advance organizer. Modern Language Journal, 82, 237-247.

Kealey, D., \& Protheroe, D. R. (1996). The effectiveness of cross-cultural training for expatriates: An assessment of the literature on the issue. International Journal of Intercultural Relations, 20(2), 141-165.

Kukulska-Hulme, A. (2010). Learning Cultures on the Move: Where are we heading?. Educational Technology \& Society, 13(4), 4-14.

Levy, M. (2007). Culture, culture learning and new technologies: towards a pedagogical framework. Language Learning \& Technology, 11(2), 104-127.

Nhung, P. T. (2016). Folktales as a Valuable Rich Cultural and Linguistic Resource to Teach a Foreign Language to Young Learners. International Journal of Education, Culture and Society, 1(1), 23-28.

Pemberton, L., Fallahkhair, S., \& Masthoff, J. (2005). Learner Centred Development of a Mobile and iTV Language Learning Support System. Educational Technology \& Society, 8(4), 52-63.

Qu, Y. (2010). Culture Understanding in Foreign Language Teaching. English Language Teaching, 3(4), 58-61.

Thanasoulas, D. (2001). The Importance of Teaching Culture in the Foreign Language Classroom. Radical Pedagogy, 3(3), 1-25.

\section{Copyrights}

Copyright for this article is retained by the author(s), with first publication rights granted to the journal.

This is an open-access article distributed under the terms and conditions of the Creative Commons Attribution license (http://creativecommons.org/licenses/by/4.0/). 